\title{
Recent Progress in Lab-on-a-Chip Technology and Its Potential Application to Clinical Diagnoses
}

\author{
Nae Yoon Lee \\ Department of BioNano Technology, Gachon University, Seongnam, Korea
}

\begin{abstract}
We present the construction of the lab-on-a-chip (LOC) system, a state-of-the-art technology that uses polymer materials (i.e., poly[dimethylsiloxane]) for the miniaturization of conventional laboratory apparatuses, and show the potential use of these microfluidic devices in clinical applications. In particular, we introduce the independent unit components of the LOC system and demonstrate how each component can be functionally integrated into one monolithic system for the realization of a LOC system. In specific, we demonstrate microscale polymerase chain reaction with the use of a single heater, a microscale sample injection device with a disposable plastic syringe and a strategy for device assembly under environmentally mild conditions assisted by surface modification techniques. In this way, we endeavor to construct a totally integrated, disposable microfluidic system operated by a single mode, the pressure, which can be applied on-site with enhanced device portability and disposability and with simple and rapid operation for medical and clinical diagnoses, potentially extending its application to urodynamic studies in molecular level.
\end{abstract}

Keywords: Lab-on-a-chip devices; Polymers; Disposable equipment; Micro-electrical-mechanical systems; Miniaturization; Diagnosis

\section{INTRODUCTION}

With the growing interest in device miniaturization, lab-on-achip (LOC) techniques have been developed as miniaturized platforms for application in various fields of research, such as analytical chemistry, biochemical assays, and environmental tests. The fast reaction times, small sample volume required, high disposability of the device, and lack of cross-contamination make these devices suitable for clinical uses. In particular, tremendous research output has been produced in the fields of microscale polymerase chain reaction (PCR) [1-11], micromixers [12-16], microvalves [17-24], and various separation and sorting applications [23,25-27] (Fig. 1). To make microfluidic devices widely applicable as commercialized platforms to a wider group of end users, mass production at low cost is a prerequisite. In early days, silicon-based materials such as glass and quartz were the main choices for materials, because charged DNA could be transferred readily inside a microscale channel. However, silicon-based microdevices are expensive, require complicated fabrication processes as well as facilities, are difficult to replicate, and are fragile. These shortcomings have turned the attention of many researchers to the search for better materials in terms of fabrication simplicity, manufacture cost, and device robustness. As a result, various plastic materials, such as poly(dimethylsiloxane) (PDMS), poly(methylmethacrylate) (PMMA) [28-32], polycarbonate (PC) [33-35], polyimide (PI) [36], and poly(ethylene terephthalate) (PET) [36] have been raised as choices for plastic materials. Besides PDMS, a transparent elastomer that has been the main choice of material for microdevice fabrication owing to easy replicability, PMMA has also been widely adopted for microfluidic applications such as DNA separation [30,32,34,37-40], detection [30,40,41], on-chip
Corresponding author: Nae Yoon Lee

Department of BioNano Technology, Gachon University, 1342 Seongnamdaero, Sujeong-gu, Seongnam 461-701, Korea

Tel: +82-31-750-8556 / Fax: +82-31-750-8774 / E-mail: nylee@gachon.ac.kr Submitted: March 12, 2013 / Accepted after revision: March 26, 2013
This is an Open Access article distributed under the terms of the Creative Commons Attribution Non-Commercial License (http://creativecommons.org/licenses/by-nc/3.0/) which permits unrestricted non-commercial use, distribution, and reproduction in any medium, provided the original work is properly cited. 


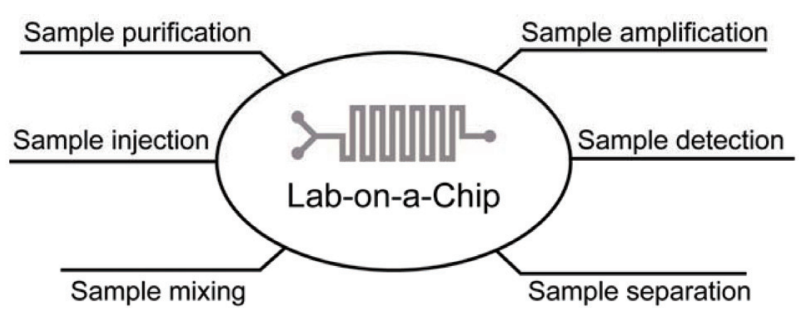

Fig. 1. Unit components making up the lab-on-a-chip (LOC) system.

PCR [42,43], and cell culture [44] owing to its particularly simple and versatile fabrication procedures, which include hot embossing [45-47], injection molding [48,49], laser ablation [50,51], reactive ion etching [52], and deep ultraviolet (UV) lithography [53].

In addition to selecting the optimum material for microdevice fabrication, each unit component of the LOC system needs to be operated under a single mode, such as pneumatic, electrokinetic, centrifugal, or magnetic forces from the point of sample injection to sample collection to truly realize the integrated system. The LOC is generally composed of several unit components, such as sample pretreatment, amplification, separation, and detection, each of which has its optimum mode of operation. For example, sample pretreatment, which is mainly composed of DNA or cell extraction and purification, can be realized by using pneumatic, centrifugal, and magnetic forces. Sample amplification, which is generally realized by performing PCR or isothermal PCR, can be realized by pneumatic force, and sample separation can be typically realized by electrokinetic force owing to the electrical charges of DNA. As a result of the various modes of actuation for optimum operation of each functional unit, integration of the whole system in a monolithic material is never an easy task.

In this study, we demonstrate the fabrication of each functional unit constructed by using PDMS and operated by pressure as a mode of actuation. Specifically, we illustrate pressuredriven sample amplification with a single heater instead of multiple heaters, a pressure-driven sample injection device without the use of a bulky syringe pump, and a strategy for device assembly at room temperature and atmospheric condition. The whole integration of these components could pave the way for the construction of a totally integrated LOC system applicable for clinical and point-of-care testing.

\section{MINIATURIZATION OF PCR}

The advent of PCR [54-56], an in vitro enzymatic amplification of nucleic acids, led to a great leap in the development of genetic research, and PCR is currently an indispensable tool for disease analyses and diagnoses. Microscale PCR has greatly shortened the overall reaction time owing to an increased heat dissipation rate and a fast transition from one temperature to another, which result from an increased surface-to-volume ratio inside a microchannel or microscale reactor. In this way, the overall reaction time for nucleic acid amplification was reduced to 6 minutes when the sample volume was reduced to $100 \mathrm{~nL}$ [57]. Among several types of microscale PCR, continuous-flow PCR [6,8,9,58-67] has received the majority of attention owing to its potential for integration with other functional units. In continuous-flow PCR, the sample liquid moves constantly inside a microchannel placed on several discrete heating sources. Nucleic acid amplification generally requries three distinct temperature zones for the denaturation, annealing, and extension steps. Therefore, multistep temperature control in PCR has been a limiting factor in device miniaturization and portability. When target amplicons are less than $300 \mathrm{bp}$ in size, the annealing and extension steps can be performed at the same temperature, which thus reduces the number of heat controls needed to two. However, a minimum of two heating apparatuses are still required for proper reaction. Thus far, researchers have come up with various heat sources, such as metal heating blocks, thin film heaters, infrared devices, halogen lamp, microwaves, platinum resistors, and induction heating when performing PCR on a chip. However, the use of multiple heating sources increases the overall footprint of the device despite the numerous advantages of involved with continuous-flow PCR such as a fast reaction time owing to the elimination of the temperature ramp time and high potential for integration with other miniaturized functional components. Some researchers introduced a new mechanism that requires the use of only a single temperature control for nucleic acid amplification: isothermal amplifications [68-70]. Although in isothermal PCR, one temperature control is sufficient for the reaction, some of these systems require the use of RNA or two sets of primers, thus restricting their use to special cases.

In our studies, we have greatly simplified the issues of temperature control by fabricating microdevices by stacking the device in multiple layers. In one study, we fabricated a 3 dimentional (3D) continuous-flow PCR microdevice by assembling 

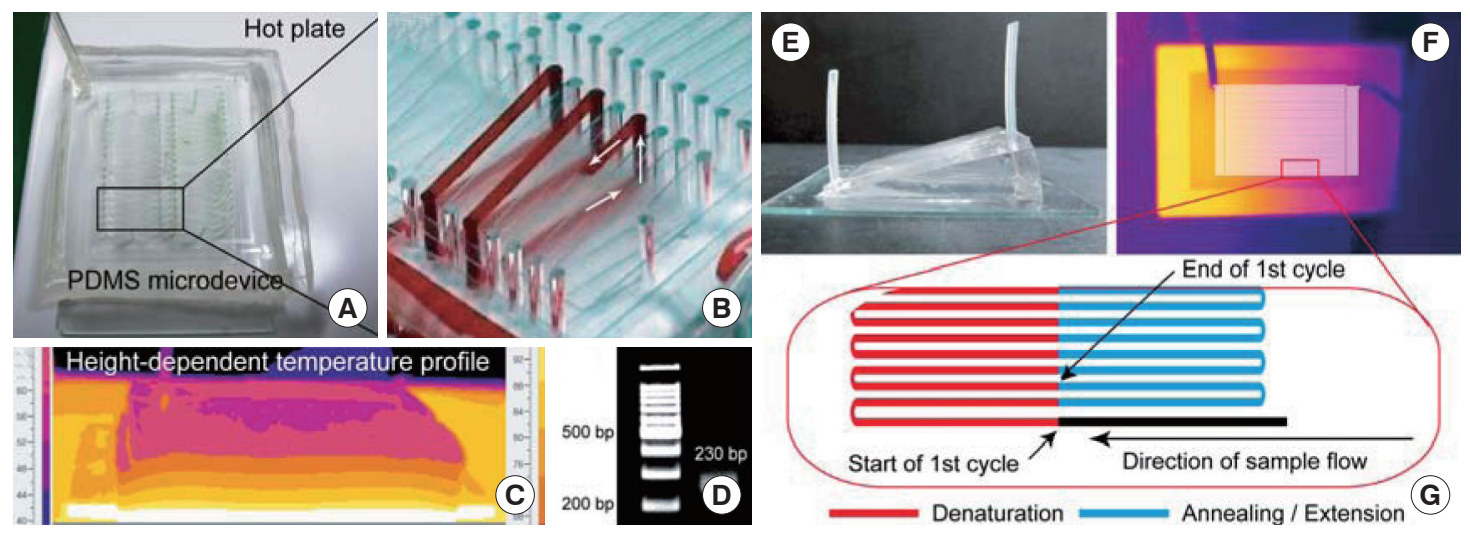

Fig. 2. (A-D) 3 dimentional (3D) continuous-flow polymerase chain reaction (PCR) microdevice. (A) A photo of a microdevice placed on a single heater. (B) Continuous up-and-down movement of a colored ink solution inside a 3D microchannel. (C) Height-dependent temperature distribution with the use of a single heater at the bottom. (D) Result of agarose gel electrophoresis displaying $230 \mathrm{bp}$ target amplicon amplified from pGEM-3Zf(+) plasmid vector. (E-G) Qiandu-shaped microdevice for performing continuous-flow PCR. (E) A photo of a microdevice. (F) Temperature distribution measured on the slanted surface when placed on a single heater. An imaginary white line was drawn to show the position of the microchannel. (G) Enlarged serpentine microchannel on which one complete thermal cycle (denaturation and annealing/extension) is defined.

two PDMS substrates in a vertical arrangement [11] (Fig. 2A-

D). Because the material used was PDMS, a kind of a rubber, the intrinsically low thermal conductivity of PDMS ( 0.16 to 0.2 $\left.\mathrm{W} \cdot \mathrm{K}^{-1} \cdot \mathrm{m}^{-1}\right)$ [71-73] when fabricated in a certain thickness generates a temperature gradient along the vertical direction. When the microdevice fabricated by using PDMS is placed on a heater, the lowest and the topmost surfaces of the PDMS display two distinct and completely isolated temperature realms, enabling two-temperature PCR with the use of a single heater. The numerical derivations required to calculate the approximate thickness for obtaining the desired surface temperature for the annealing/extension procedure were also derived. This new 3D fluidic configuration enables the use of only a single heater to control two temperatures simply by controlling the thickness of the PDMS substrate. In this study, we successfully amplified a 230-bp plasmid vector by use of a commercially available and highly cost-effective hot plate as a single heating source.

In another study, we fabricated, a qiandu (right triangular prism)-shaped microdevice with PDMS [74] (Fig. 2E-G). In this qiandu-shaped microdevice, a height-dependent thermal gradient was established linearly on the slanted plane of the microdevice simply by heating the microdevice with a single heater, because the heat-insulating characteristic of the PDMS material was used. Furthermore, the resulting height-dependent temperature gradient generated on the slanted plane can retain all possible temperatures existing within the lowest and highest temperature ranges created at the top and bottom of the qian- du-shaped microdevice, respectively, eventually creating temperature zones covering the denaturation, annealing, and extension reactions necessary for performing PCR. In this way, the number of heaters is reduced to one, and the overall footprint of the microdevice is subsequently decreased, both of which are considered two main drawbacks of current continuous-flow PCR. Although similar concepts were raised by other researchers $[75,76]$, the formation of the thermal gradient required a cooling element. Using the qiandu-shaped PDMS microdevice, we have successfully amplified a specific sequence in thyroid transcription factor-1 [77-79], which is an effective marker of lung and thyroid carcinomas, by use of a commercially available hot plate and without the use of a cooling system.

\section{MINIATURIZATION OF A SAMPLE ACTUATION DEVICE}

Simplification of the sample injection process in a typical microfluidic experiment is one of the key issues for the successful miniaturization and integration of a variety of analytical and bioanalytical reactions in a portable micro Total Analysis Systems. Although the footprint of many microdevices was demonstrated over a decade ago, the issues regarding the use of essential external accessories such as heaters for temperature control and pumps for sample actuation hinder total integration [80,81], thus restricting practical applicability in on-site and direct field uses. Although some efforts have been made to sim- 
plify the heating apparatuses, the issue of sample injection or actuation remains a bottleneck when enhancing the portability of the device. For this reason, researchers have endeavored to simplify and automate the sample injection issue by combining gravitational force and liquid surface tension, particularly for sperm cell sorting [82]. Some exploited the potential of the highly gas-permeable nature of PDMS for a stand-alone and selfpowered integrated device for blood assay [83], and some introduced a self-contained, chemically powered chip utilizing the catalytic decomposition of $\mathrm{H}_{2} \mathrm{O}_{2}$ to generate oxygen that could be used for sample injection [84]. Others utilized the intrinsic high gas solubility of PDMS to generate negative pressure inside a microchannel by degassing the microdevice before introducing a sample for DNA and protein analyses $[85,86]$. In addition to these attempts, various other forces have been used, such as convection flow [87-89], the thermosiphone effect [90,91], and magnetic field-based flow [92], with the aid of relatively simplified peripherals such as a heater and a magnet. However, owing to specialty in actuation principle, the abovementioned modes can hardly be integrated with other functional units. For this reason, pressure-driven flow $[93,94]$ has remained one of the main modes for sample actuation owing to its high stability and reproducibility in injection performance with relatively simple operation regardless of the fact that the use of a bulky and expensive syringe pump is required.

In our study, we attempted to simplify the sample injection issue by creating a pressure gradient along the length of a fluidic channel which was fabricated with gas-permeable PDMS. The pressure gradient was created simply by compressing the air inside the gas-permeable fluidic conduit by using a disposable plastic syringe, and the resulting difference in the volume of air retained at the anterior and posterior ends of the sample accounts for the fluid movement. Here, we have developed a miniaturized and disposable pumping unit using a disposable plastic syringe and have investigated its feasibility for conducting continuous-flow PCR on chip without the use of a bulky external pumping apparatus (Fig. 3).

Unlike in earlier studies demonstrating power-free sample injection performance where relatively shorter channels were examined, continuous-flow PCR typically requires an extremely long microchannel exceeding $2 \mathrm{~m}$ in length for reaction, and we have successfully demonstrated the potential of integrating a miniaturized sample injection device with a continuous-flow PCR device to realize a self-powered PCR platform, which greatly enhances device portability and enables multiplexing.

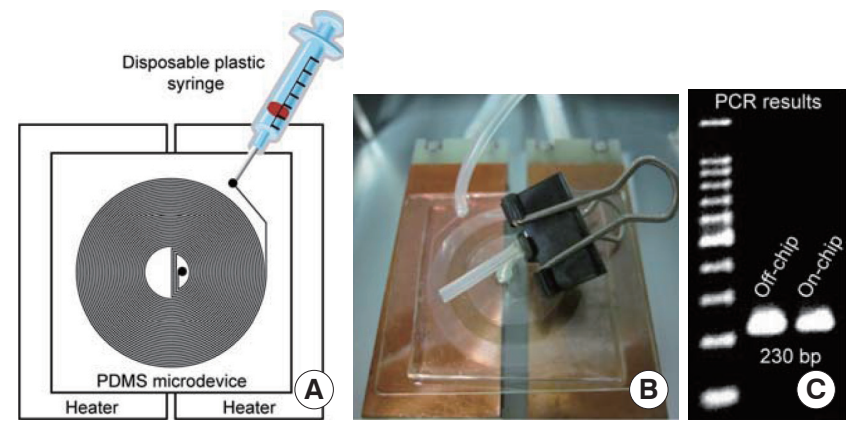

Fig. 3. Scheme and result demonstrating sample injection employing a disposable plastic syringe. (A) A schematic illustration showing a spiral microchannel fabricated with poly(dimethylsiloxane) (PDMS) and placed on two heating blocks for performing continuous-flow polymerase chain reaction (PCR). (B) A photo showing sample flow inside a spiral microchannel actuated by a disposable plastic syringe. (C) Result of agarose gel electrophoresis amplifying a 230-bp target amplicon from the pGEM-3Zf(+) plasmid vector. Target band intensities were comparable when performed off-chip and on-chip.

The proposed sample injection scheme replaces a traditional bulky external pumping apparatus with a disposable plastic syringe and therefore greatly enhances overall device portability as well as accessibility to general users. In our study, we used a spiral microchannel. Compared with the more commonly adopted serpentine structure, spiral architecture effectively controls temperatures and therefore prevents unwanted amplification of nonspecific byproducts such as primer-dimers. In addition, the overall device footprint is reduced. Despite the many advantages of using spiral architecture as mentioned above, it is difficult to precisely regulate the liquid flow rate when the structure is used for continuous-flow PCR, which results in regionally different residence times in each amplification cycle. To overcome the disadvantages of adopting the spiral configuration while retaining its advantages, we attempted to couple the spiral microchannel with the proposed sample injection scheme, because the flow of the sample diminishes gradually as it moves toward the end of the fluidic conduit owing to the gradual decrease in the pressure gradient. This synchronized sample residence time in each temperature zone carries throughout the entire reaction of the continuous-flow PCR. As a proof-of-concept experiment, a 230-bp gene fragment was successfully amplified from a pGEM-3Zf $(+)$ plasmid vector, and as a practical application, the first 282 bp of the interferon-beta (IFN- $\beta$ ) promoter [95] was also successfully amplified from a human genomic DNA. 


\section{MICRODEVICE ASSEMBLY}

Bonding is one of the critical issues in microfluidic device fabrication. In the early days of this technology, microdevices were fabricated on the surface of glass or quartz, because the applications were mainly on microscale separation, driven by an electro-osmotic flow $[96,97]$ for sample movement. However, because of complicated fabrication processes such as anodic or fusion bonding, which involve high temperature and pressure as well as voltage application, polymer materials have received much attention in microdevice fabrication. PDMS, a silicone elastomer, has been most widely adopted as a material for microdevice fabrication owing to a simple molding process, optical transparency in visible wavelengths, high thermal resistance, inexpensiveness, and biocompatibility. In addition, robust and stable device assembly can be achieved by forming surface hydroxyl groups via plasma treatment, corona discharges, and UV/ozone treatments, followed by thermal curing. However, microdevices fabricated on PDMS, a thermosetting resin, do not generally form irreversible bonds with plastic materials, thermoplastic resin, regardless of oxygen plasma treatment and a subsequent thermal process. Bonding between PDMS and various materials can provide useful functions, such as when fabricating microvalves, which require an elastomeric membrane, or when immobilizing biomolecules, because PDMSpolymer hybrid microdevices can provide versatile surface functionalities. For this reason, many researchers have strived to find alternatives to realize PDMS-plastic assemblies. In our study, we introduced a new scheme called "chemical gluing" for bonding PDMS at room temperature by anchoring chemical functionalities on the surfaces of PDMS substrates [36]. This new bonding strategy was realized by anchoring amine-terminated silane (aminosilane) on one PDMS substrate and epoxyterminated silane (epoxysilane) on the other PDMS substrate via a silane coupling reaction followed by amine-epoxy bond formation. It is well known that the reaction between the amine and the epoxy groups leads to the formation of a strong amineepoxy bond $[98,99]$ at room temperature, which can therefore act as chemical glue enabling robust and permanent bonding in a facile manner without the use of heat (Fig. 4A).

Using this method, the PDMS was permanently bonded with various substrates, such as PMMA, PET, and PI, and the bonded device endured tremendous amounts of sample introduction. The per-minute injection volume was nearly 1,000 to 2,000 times that of the total internal volume of the microchan-

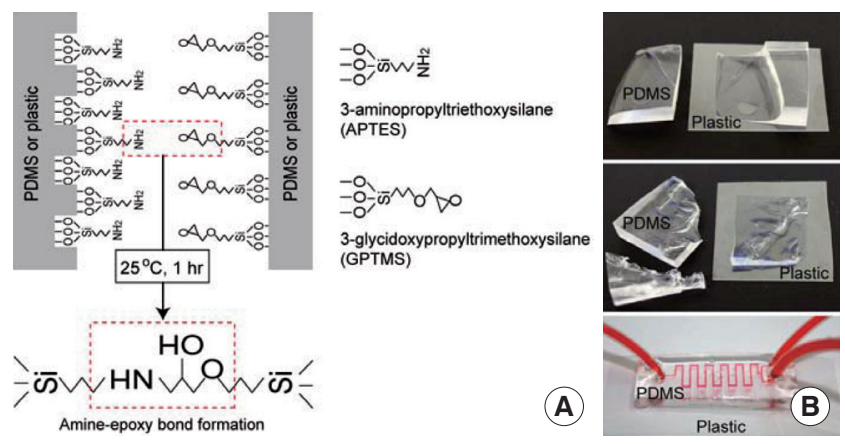

Fig. 4. (A) Schematic illustration demonstrating the mechanism for bonding poly(dimethylsiloxane) (PDMS) and plastic substrates, independently grafted with either aminosilane or epoxysilane, under room temperature and atmospheric pressure condition. A strong amine-epoxy bond is formed after 1 hour of physical contact resulting in permanent assembly. (B) Results of physical detachment of the bonded assemblies and colored ink flow inside the bonded microchannel.

nel used (Fig. 4B). The successful surface modifications were confirmed by performing various surface characterizations such as X-ray photoelectron spectroscopy, contact angle measurement, and fluorescence analyses, and the bond strength of the PDMS-PDMS homogeneous or PDMS-plastic heterogeneous assemblies were analyzed by performing pulling, tearing, and leakage tests. The introduced chemical gluing is highly advantageous, especially when thermally fragile microscale components such as optical waveguides and fibers as well as cells or biomolecules must be integrated and incorporated into the microdevice before the bonding. The obtained robust seal could provide a cell-friendly or biomolecule-friendly microenvironment, thus allowing in-depth research in various biological studies on a microscale. Also, the dual functionalities obtained as a consequence of the chemical gluing were demonstrated to be highly effective for achieving directed and targeted immobilization to a predetermined site inside the microchannel.

\section{CONCLUSIONS}

In this study, several unit components were introduced, such as a continuous-flow PCR unit, sample injection unit, and a mechanism for device assembly under room temperature and atmospheric pressure condition. All the unit components were fabricated by using a PDMS elastomer, and sample flow was actuated by pressure. Pressure-actuated sample flow inside a microchannel with the use of a disposable plastic syringe and the operation of the device with a single heater enabled overall down- 
sizing of the device footprint and replaced the use of bulky and expensive peripheral accessories such as a pump and heaters. Also, the room temperature bonding strategy enabled rapid assembling of the device within 1 hour, thus paving the way for the mass production of the microdevice. Successful amplification of practical disease markers ensures the potential application of the microdevices for medical and clinical diagnoses, extending its application to urodynamic studies in molecular level, with enhanced device portability and disposability and the elimination of sample degradation and contamination issues.

\section{CONFLICT OF INTEREST}

No potential conflict of interest relevant to this article was reported.

\section{ACKNOWLEDGEMENTS}

This work was supported by the Gachon University research fund of 2013 (GCU-2013-R062).

\section{REFERENCES}

1. Kricka LJ, Wilding P. Microchip PCR. Anal Bioanal Chem 2003;377: 820-5.

2. Zhang $\mathrm{C}, \mathrm{Xu}$ J, Ma W, Zheng W. PCR microfluidic devices for DNA amplification. Biotechnol Adv 2006;24:243-84.

3. Shen K, Chen X, Guo M, Cheng J. A microchip-based PCR device using flexible printed circuit technology. Sens Actuator B 2005;105: 251-8.

4. Christensen TB, Bang DD, Wolff A. Multiplex polymerase chain reaction (PCR) on a SU-8 chip. Microelectron Eng 2008;85:1278-81.

5. Zhang C, Xing D. Miniaturized PCR chips for nucleic acid amplification and analysis: latest advances and future trends. Nucleic Acids Res 2007;35:4223-37.

6. Kopp MU, Mello AJ, Manz A. Chemical amplification: continuousflow PCR on a chip. Science 1998;280:1046-8.

7. Hashimoto M, Chen PC, Mitchell MW, Nikitopoulos DE, Soper SA, Murphy MC. Rapid PCR in a continuous flow device. Lab Chip 2004;4:638-45.

8. Sun Y, Satyanarayan MV, Nguyen NT, Kwok YC. Continuous flow polymerase chain reaction using a hybrid PMMA-PC microchip with improved heat tolerance. Sens Actuator B 2008;130:836-41.

9. Zhang Q, Wang W, Zhang H, Wang Y. Temperature analysis of continuous-flow micro-PCR based on FEA. Sens Actuator B 2002;
82:75-81

10. Wu W, Kang KT, Lee NY. Bubble-free on-chip continuous-flow polymerase chain reaction: concept and application. Analyst 2011; 136:2287-93.

11. Wu W, Lee NY. Three-dimensional on-chip continuous-flow polymerase chain reaction employing a single heater. Anal Bioanal Chem 2011;400:2053-60.

12. Hessel V, Lowe H, Schonfeld F. Micromixers: a review on passive and active mixing principles. Chem Eng Sci 2005;60:2479-501.

13. Lee SW, Lee SS. Rotation effect in split and recombination micromixing. Sens Actuator B 2008;129:364-71.

14. Yang SY, Lin JL, Lee GB. A vortex-type micromixer utilizing pneumatically driven membranes. J Micromech Microeng 2009;19: 035020 .

15. Lee NY, Yamada M, Seki M. Development of a passive micromixer based on repeated fluid twisting and flattening, and its application to DNA purification. Anal Bioanal Chem 2005;383:776-82.

16. Tseng HY, Wang CH, Lin WY, Lee GB. Membrane-activated microfluidic rotary devices for pumping and mixing. Biomed Microdevices 2007;9:545-54.

17. LaCroix-Fralish A, Templeton EJ, Salin ED, Skinner CD. A rapid prototyping technique for valves and filters in centrifugal microfluidic devices. Lab Chip 2009;9:3151-4.

18. Unger MA, Chou HP, Thorsen T, Scherer A, Quake SR. Monolithic microfabricated valves and pumps by multilayer soft lithography. Science 2000;288:113-6.

19. Oh KW, Park C, Namkoong K, Kim J, Ock KS, Kim S, et al. Worldto-chip microfluidic interface with built-in valves for multichamber chip-based PCR assays. Lab Chip 2005;5:845-50.

20. Pitchaimani K, Sapp BC, Winter A, Gispanski A, Nishida T, Hugh Fan Z. Manufacturable plastic microfluidic valves using thermal actuation. Lab Chip 2009;9:3082-7.

21. Chien LJ, Wang JH, Hsieh TM, Chen PH, Chen PJ, Lee DS, et al. A micro circulating PCR chip using a suction-type membrane for fluidic transport. Biomed Microdevices 2009;11:359-67.

22. Yamada M, Seki M. Nanoliter-sized liquid dispenser array for multiple biochemical analysis in microfluidic devices. Anal Chem 2004; 76:895-9.

23. Lee NY, Yamada M, Seki M. Pressure-driven sample injection with quantitative liquid dispensing for on-chip electrophoresis. Anal Sci 2004;20:483-7.

24. Lee NY, Yamada M, Seki M. Control-free air vent system for ultralow volume sample injection on a microfabricated device. Anal Sci 2005;21:465-8.

25. Holcomb RE, Kraly JR, Henry CS. Electrode array detector for mi- 
crochip capillary electrophoresis. Analyst 2009;134:486-92.

26. Jung Y, Choi Y, Han KH, Frazier AB. Six-stage cascade paramagnetic mode magnetophoretic separation system for human blood samples. Biomed Microdevices 2010;12:637-45.

27. Yamada M, Nakashima M, Seki M. Pinched flow fractionation: continuous size separation of particles utilizing a laminar flow profile in a pinched microchannel. Anal Chem 2004;76:5465-71.

28. Xu F, Jabasini M, Baba Y. DNA separation by microchip electrophoresis using low-viscosity hydroxypropylmethylcellulose-50 solutions enhanced by polyhydroxy compounds. Electrophoresis 2002;23:3608-14.

29. Soper SA, Henry AC, Vaidya B, Galloway M, Wabuyele M, McCarley RL. Surface modification of polymer based microfluidic devices. Anal Chim Acta 2002;470:87-99.

30. Lee GB, Chen SH, Huang GR, Sung WC, Lin YH. Microfabricated plastic chips by hot embossing methods and their applications for DNA separation and detection. Sens Actuator B 2001;75:142-8.

31. Lin YW, Huang MJ, Chang HT. Analysis of double-stranded DNA by microchip capillary electrophoresis using polymer solutions containing gold nanoparticles. J Chromatogr A 2003;1014:47-55.

32. Chen YH, Chen SH. Analysis of DNA fragments by microchip electrophoresis fabricated on poly(methyl methacrylate) substrates using a wire-imprinting method. Electrophoresis 2000;21:165-70.

33. Chen J, Wabuyele M, Chen H, Patterson D, Hupert M, Shadpour H, et al. Electrokinetically synchronized polymerase chain reaction microchip fabricated in polycarbonate. Anal Chem 2005;77:658-66.

34. Chen YH, Wang WC, Young KC, Chang TT, Chen SH. Plastic microchip electrophoresis for analysis of PCR products of hepatitis $\mathrm{C}$ virus. Clin Chem 1999;45:1938-43.

35. Ye MY, Yin XF, Fang ZL. DNA separation with low-viscosity sieving matrix on microfabricated polycarbonate microfluidic chips. Anal Bioanal Chem 2005;381:820-7.

36. Lee NY, Chung BH. Novel poly(dimethylsiloxane) bonding strategy via room temperature "chemical gluing". Langmuir 2009;25: 3861-6.

37. Du XG, Fang ZL. Static adsorptive coating of poly(methyl methacrylate) microfluidic chips for extended usage in DNA separations. Electrophoresis 2005;26:4625-31.

38. Sassi AP, Paulus A, Cruzado ID, Bjornson T, Hooper HH. Rapid, parallel separations of d1S80 alleles in a plastic microchannel chip. J Chromatogr A 2000;894:203-17.

39. Sung WC, Lee GB, Tzeng CC, Chen SH. Plastic microchip electrophoresis for genetic screening: the analysis of polymerase chain reactions products of fragile X (CGG)n alleles. Electrophoresis 2001; 22:1188-93.
40. Graß B, Neyer A, Johnck M, Siepe D, Eisenbeiß F, Weber G, et al. A new PMMA-microchip device for isotachophoresis with integrated conductivity detector. Sens Actuator B 2001;72:249-58.

41. Wang J, Pumera M, Chatrathi MP, Escarpa A, Konrad R, Griebel A, et al. Towards disposable lab-on-a-chip: poly(methylmethacrylate) microchip electrophoresis device with electrochemical detection. Electrophoresis 2002;23:596-601.

42. Hashimoto M, Barany F, Soper SA. Polymerase chain reaction/ligase detection reaction/hybridization assays using flow-through microfluidic devices for the detection of low-abundant DNA point mutations. Biosens Bioelectron 2006;21:1915-23.

43. Liu D, Zhou X, Zhong R, Ye N, Chang G, Xiong W, et al. Analysis of multiplex PCR fragments with PMMA microchip. Talanta 2006; 68:616-22.

44. Petronis S, Stangegaard M, Christensen CB, Dufva M. Transparent polymeric cell culture chip with integrated temperature control and uniform media perfusion. Biotechniques 2006;40:368-76.

45. Chen Z, Gao Y, Lin J, Su R, Xie Y. Vacuum-assisted thermal bonding of plastic capillary electrophoresis microchip imprinted with stainless steel template. J Chromatogr A 2004;1038:239-45.

46. Becker H, Heim U. Hot embossing as a method for the fabrication of polymer high aspect ratio structures. Sens Actuator A 2000;83: 130-5.

47. Becker H, Heim U. Polymer hot embossing with silicon master structures. Sens Mater 1999;11:297-304.

48. McCormick RM, Nelson RJ, Alonso-Amigo MG, Benvegnu DJ, Hooper HH. Microchannel electrophoretic separations of DNA in injection-molded plastic substrates. Anal Chem 1997;69:2626-30.

49. Ogura M, Agata Y, Watanabe K, McCormick RM, Hamaguchi Y, Aso Y, et al. RNA chip: quality assessment of RNA by microchannel linear gel electrophoresis in injection-molded plastic chips. Clin Chem 1998;44:2249-55.

50. Cheng JY, Wei CW, Hsu KH, Young TH. Direct-write laser micromachining and universal surface modification of PMMA for device development. Sens Actuator B 2004;99:186-96.

51. Lin YC, Ho HC, Tseng CK, Hou SQ. A poly-methylmethacrylate electrophoresis microchip with sample preconcentrator. J Micromech Microeng 2001;11:189-94.

52. Ceriotti L, Weible K, de Rooij NF, Verpoorte E. Rectangular channels for lab-on-a-chip applications. Microelectron Eng 2003;67-68: $865-71$

53. Utsumi Y, Ozaki M, Terabe S, Hattori T. Improvement of capillary electrophoresis property for microchannels fabricated by deep Xray lithography. Microsyst Technol 2005;11:235-9.

54. Saiki RK, Scharf S, Faloona F, Mullis KB, Horn GT, Erlich HA, et al. 
Enzymatic amplification of beta-globin genomic sequences and restriction site analysis for diagnosis of sickle cell anemia. Science 1985;230:1350-4.

55. Mullis KB, Faloona FA. Specific synthesis of DNA in vitro via a polymerase-catalyzed chain reaction. Methods Enzymol 1987;155: 335-50.

56. Mullis KB. The unusual origin of the polymerase chain reaction. Sci Am 1990;262:56-61, 64-5.

57. Neuzil P, Zhang C, Pipper J, Oh S, Zhuo L. Ultra fast miniaturized real-time PCR: 40 cycles in less than six minutes. Nucleic Acids Res 2006;34:e77.

58. Crews N, Wittwer C, Palais R, Gale B. Product differentiation during continuous-flow thermal gradient PCR. Lab Chip 2008;8:91924.

59. Hartung R, Brosing A, Sczcepankiewicz G, Liebert U, Hafner N, Durst $\mathrm{M}$, et al. Application of an asymmetric helical tube reactor for fast identification of gene transcripts of pathogenic viruses by micro flow-through PCR. Biomed Microdevices 2009;11:685-92.

60. Park N, Kim S, Hahn JH. Cylindrical compact thermal-cycling device for continuous-flow polymerase chain reaction. Anal Chem 2003;75:6029-33.

61. Obeid PJ, Christopoulos TK, Crabtree HJ, Backhouse CJ. Microfabricated device for DNA and RNA amplification by continuousflow polymerase chain reaction and reverse transcription-polymerase chain reaction with cycle number selection. Anal Chem 2003;75:288-95.

62. Schaerli Y, Wootton RC, Robinson T, Stein V, Dunsby C, Neil MA, et al. Continuous-flow polymerase chain reaction of single-copy DNA in microfluidic microdroplets. Anal Chem 2009;81:302-6.

63. Sun K, Yamaguchi A, Ishida Y, Matsuo S, Misawa H. A heater-integrated transparent microchannel chip for continuous-flow PCR. Sens Actuators B 2002;84:283-9.

64. Nakayama T, Kurosawa Y, Furui S, Kerman K, Kobayashi M, Rao SR, et al. Circumventing air bubbles in microfluidic systems and quantitative continuous-flow PCR applications. Anal Bioanal Chem 2006;386:1327-33.

65. Liu HB, Gong HQ, Ramalingam N, Jiang Y, Dai CC, Hui KMJ. Micro air bubble formation and its control during polymerase chain reaction (PCR) in polydimethylsiloxane (PDMS) microreactors. J Micromech Microeng 2007;17:2055-64.

66. Hong JW, Fujii T, Seki M, Yamamoto T, Endo I. Integration of gene amplification and capillary gel electrophoresis on a polydimethylsiloxane-glass hybrid microchip. Electrophoresis 2001;22:328-33.

67. Lopez J, Prezioso V. A better way to optimize: two-step gradient PCR. Eppendorf BioNews Appl Note 2001;16:3-4.
68. Mazutis L, Araghi AF, Miller OJ, Baret JC, Frenz L, Janoshazi A, et al. Droplet-based microfluidic systems for high-throughput single DNA molecule isothermal amplification and analysis. Anal Chem 2009;81:4813-21.

69. Asiello PJ, Baeumner AJ. Miniaturized isothermal nucleic acid amplification, a review. Lab Chip 2011;11:1420-30.

70. Fang X, Chen $\mathrm{H}$, Yu S, Jiang X, Kong J. Predicting viruses accurately by a multiplex microfluidic loop-mediated isothermal amplification chip. Anal Chem 2011;83:690-5.

71. Prakash AR, Adamia S, Sieben V, Pilarski P, Pilarski LM, Backhouse CJ. Small volume PCR in PDMS biochips with integrated fluid control and vapor barrier. Sens Actuator B 2006;113:398-409.

72. McDonald JC, Duffy DC, Anderson JR, Chiu DT, Wu H, Schueller OJ, et al. Fabrication of microfluidic systems in poly(dimethylsiloxane). Electrophoresis 2000;21:27-40.

73. Shin YS, Cho K, Lim SH, Chung S, Park SJ, Chung C, et al. PDMSbased micro PCR chip with parylene coating. J Micromech Microeng 2003;13:768-74.

74. Wu W, Loan KT, Lee NY. Flow-through PCR on a 3D qiandushaped polydimethylsiloxane (PDMS) microdevice employing a single heater: toward microscale multiplex PCR. Analyst 2012;137: 2069-76.

75. Mao H, Yang T, Cremer PS. A microfluidic device with a linear temperature gradient for parallel and combinatorial measurements. J Am Chem Soc 2002;124:4432-5.

76. Mao H, Holden MA, You M, Cremer PS. Reusable platforms for high-throughput on-chip temperature gradient assays. Anal Chem 2002;74:5071-5.

77. Jiang B, Wu GP, Zhao YJ, Wang SC. Transcription expression and clinical significance of TTF-1 mRNA in pleural effusion of patients with lung cancer. Diagn Cytopathol 2008;36:849-54.

78. Ordonez NG. Thyroid transcription factor-1 is a marker of lung and thyroid carcinomas. Adv Anat Pathol 2000;7:123-7.

79. Oliveira AM, Tazelaar HD, Myers JL, Erickson LA, Lloyd RV. Thyroid transcription factor-1 distinguishes metastatic pulmonary from well-differentiated neuroendocrine tumors of other sites. Am J Surg Pathol 2001;25:815-9.

80. Burns MA, Johnson BN, Brahmasandra SN, Handique K, Webster JR, Krishnan M, et al. An integrated nanoliter DNA analysis device. Science 1998;282:484-7.

81. Chen L, Manz A, Day PJ. Total nucleic acid analysis integrated on microfluidic devices. Lab Chip 2007;7:1413-23.

82. Cho BS, Schuster TG, Zhu X, Chang D, Smith GD, Takayama S. Passively driven integrated microfluidic system for separation of motile sperm. Anal Chem 2003;75:1671-5. 
83. Dimov IK, Basabe-Desmonts L, Garcia-Cordero JL, Ross BM, Park Y, Ricco AJ, et al. Stand-alone self-powered integrated microfluidic blood analysis system (SIMBAS). Lab Chip 2011;11:845-50.

84. Qin L, Vermesh O, Shi Q, Heath JR. Self-powered microfluidic chips for multiplexed protein assays from whole blood. Lab Chip 2009;9:2016-20.

85. Hosokawa K, Sato K, Ichikawa N, Maeda M. Power-free poly(dimethylsiloxane) microfluidic devices for gold nanoparticle-based DNA analysis. Lab Chip 2004;4:181-5.

86. Hosokawa K, Omata M, Sato K, Maeda M. Power-free sequential injection for microchip immunoassay toward point-of-care testing. Lab Chip 2006;6:236-41.

87. Krishnan M, Ugaz VM, Burns MA. PCR in a Rayleigh-Bénard convection cell. Science 2002;298:793.

88. Krishnan M, Agrawal N, Burns MA, Ugaz VM. Reactions and fluidics in miniaturized natural convection systems. Anal Chem 2004; 76:6254-65

89. Wheeler EK, Benett W, Stratton P, Richards J, Chen A, Christian A, et al. Convectively driven polymerase chain reaction thermal cycler. Anal Chem 2004;76:4011-6.

90. Chen Z, Qian S, Abrams WR, Malamud D, Bau HH. Thermosiphonbased PCR reactor: experiment and modeling. Anal Chem 2004; 76:3707-15.

91. Chung KH, Park SH, Choi YH. A palmtop PCR system with a disposable polymer chip operated by the thermosiphon effect. Lab Chip 2010;10:202-10.
92. Sun Y, Kwok YC, Nguyen NT. A circular ferrofluid driven microchip for rapid polymerase chain reaction. Lab Chip 2007;7:1012-7.

93. Curcio M, Roeraade J. Continuous segmented-flow polymerase chain reaction for high-throughput miniaturized DNA amplification. Anal Chem 2003;75:1-7.

94. Chou CF, Changrani R, Roberts P, Sadler D, Burdon J, Zenhausern F, et al. A miniaturized cyclic PCR device: modeling and experiments. Microelectron Eng 2002;61-62:921-5.

95. Chen S, Short JA, Young DF, Killip MJ, Schneider M, Goodbourn S, et al. Heterocellular induction of interferon by negative-sense RNA viruses. Virology 2010;407:247-55.

96. Nashabeh W, Smith JT, el Rassi Z. Studies in capillary zone electrophoresis with a post-column multiple capillary device for fraction collection and stepwise increase in electroosmotic flow during analysis. Electrophoresis 1993;14:407-16.

97. Duffy DC, Gillis HL, Lin J, Sheppard NF Jr, Kellogg GJ. Microfabricated centrifugal microfluidic systems: characterization and multiple enzymatic assays. Anal Chem 1999;71:4669-78.

98. Mateo C, Torres R, Fernandez-Lorente G, Ortiz C, Fuentes M, Hidalgo A, et al. Epoxy-amino groups: a new tool for improved immobilization of proteins by the epoxy method. Biomacromolecules 2003;4:772-7.

99. Mateo C, Abian O, Fernandez-Lorente G, Pedroche J, FernandezLafuente R, Guisan JM, et al. Epoxy sepabeads: a novel epoxy support for stabilization of industrial enzymes via very intense multipoint covalent attachment. Biotechnol Prog 2002;18:629-34. 